\title{
Design and Synthesis of Cysteine Proteases Inhibitors ${ }^{\dagger}$
}

\author{
Florenci V. Gonzalez *, Lledó Bou-Iserte and Santiago Royo \\ Universitat Jaume I, 12071 Castelló, Spain \\ * Correspondence: fgonzale@uji.es \\ + Presented at the 2nd Molecules Medicinal Chemistry Symposium (MMCS): \\ Facing Novel Challenges in Drug Discovery, Barcelona, Spain, 15-17 May 2019.
}

Published: 26 August 2019

Keywords: proteases; inhibitors; malaria; trypanosomiasis; leishmaniasis

Cysteine proteases belonging to the papain superfamily have been recognized as interesting therapeutic targets for the search for new drugs against infectious tropical diseases such as malaria (falcipain), Chagas' disease (curtain), leishmaniasis, and Sleeping sickness (rhodesian), and a number of human pathologies, including cancer, Alzheimer's disease, and osteoporosis (cathepsins). We have reported irreversible inhibitors Dipeptidyl epoxyesters ( $\mathrm{k}_{\text {inac }} / \mathrm{K}_{\mathrm{I}}$ up to $92,090 \mathrm{M}^{-1} / \mathrm{s}^{-1}$ ) [1], Dipeptidyl enoates ( $\mathrm{k}_{\text {inac }} / \mathrm{K}_{\mathrm{I}}$ up to $1,530,000 \mathrm{M}^{-1} / \mathrm{s}^{-1}$ ) [2,3], Aminoacyl epoxysulfones [4], and also reversible inhibitors Dipeptidyl nitroalkenes ( $\mathrm{IC}_{50}$ up to $0.44 \mathrm{nM}$ ) [5] as inhibitors of parasitic cysteine proteases and cathepsins. Inhibition kinetics and computational studies have been used to study the mode of action of these inhibitors.

\section{References}

1 González, F.V.; Izquierdo, J.; Rodríguez, S.; McKerrow, J.K.; Hansell, E. Fipeptidyl- $\alpha, \beta$-epoxyesters as potent irreversible inhibitors of the cysteine proteases cruzain and rhodesain. Bioorg. Med. Chem. Lett. 2007, 17, 6697-6700.

2 Royo, S.; Rodríguez, S.; Schirmeister, T.; Kesselring, J.; Kaiser, M.; González, F.V. Dipeptidyl enoates as potent rhodesain inhibitors that display a dual mode of action. Chem. Med. Chem. 2015, 10, 1484-1487.

3 Royo, S.; Schirmeister, T.; Kaiser, M.; Jung, S.; Rodríguez, S.; Bautista, J. M.; González, F. V. Antiprotozoal and cysteine proteases inhibitory activity of dipeptidyl enoates. Bioorg. Med. Chem. 2018, 26, 4624-4634.

4 Latorre, A.; Rodríguez, S.; González, F.V.; Florea, B.I.; Overkleeft, H.S. Synthetic studies on the preparation of alanyl epoxysulfones as cathepsin cysteine protease electrophilic traps. J. Org. Chem. 2015, 80, 7752-7756.

5 Latorre, A.; Schirmeister, T.; Kesselring, J.; Jung, S.; Johé, P.; Hellmich, U.A.; Heilos, A.; Engels, B.; Krauth-Siegel, R.L.; Dirdjaja, N.; et al. Dipeptidyl Nitroalkenes as Potent Reversible Inhibitors of Cysteine Proteases Rhodesain and Cruzain. ACS Med. Chem. Lett. 2016, 7, 1073-1076.

(C) 2019 by the authors. Licensee MDPI, Basel, Switzerland. This article is an open access article distributed under the terms and conditions of the Creative Commons Attribution (CC BY) license (http://creativecommons.org/licenses/by/4.0/). 